\title{
Marie A. Capitanio, MD, FACR (1930-2015)
}

\author{
Eric N. Faerber ${ }^{1}$
}

Received: 26 October 2015 / Accepted: 29 October 2015 / Published online: 21 November 2015

(C) Springer-Verlag Berlin Heidelberg 2015

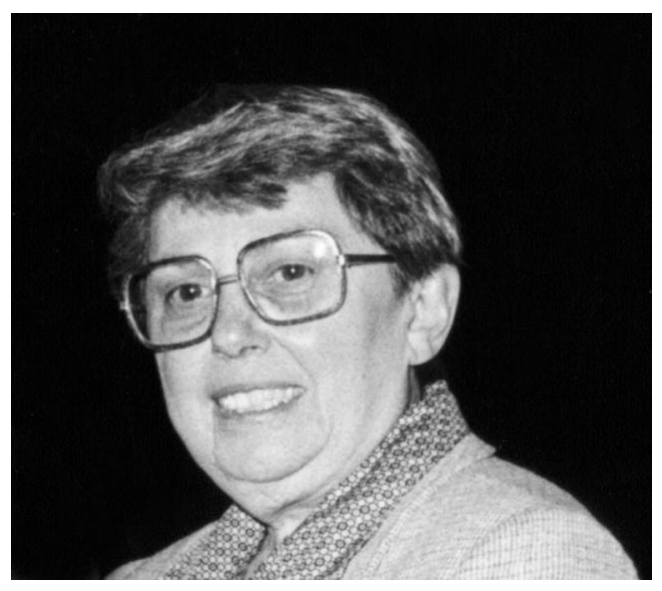

Marie Angeline Capitanio, a pioneer of pediatric radiology, passed away Sept. 13, 2015. She was born Jan. 26, 1930, in Philadelphia and grew up not far from the hospital where she would become the director of radiology in 1974.

After completing her high school education, she was briefly employed as a long-distance telephone operator. She subsequently graduated first in her class as a nurse from Pennsylvania Hospital in Philadelphia. She then graduated magna cum laude with a bachelor of science from Lincoln Memorial University in Harrogate, TN, and received the Algernon Sydney Sullivan Medallion. She

Eric N. Faerber

Eric.faerber@tenethealth.com

1 Department of Radiology, St. Christopher's Hospital for Children, 160 E. Erie Ave., Philadelphia, PA 19134-1095, USA entered medical school at the Medical College of Pennsylvania in Philadelphia, graduating in 1959. After graduation she completed a rotating internship at Episcopal Hospital and a radiology residency at Temple University Hospital in Philadelphia.

Marie was a fellow in pediatric radiology at Children's Hospital in Pittsburgh from 1963 to 1964, where she worked with world-renowned pediatric radiologist John Caffey, "the father of pediatric radiology." Her association with Dr. Caffey led her to becoming an early member of the John Caffey Pediatric Radiology Society, which continues to this day.

After completing her pediatric radiology fellowship in 1964, Marie was recruited by John Kirkpatrick to join him as an attending radiologist at St. Christopher's Hospital for Children in Philadelphia. This was the beginning of an illustrious radiology career, and the synergy between John and Marie led to the production of many landmark and diverse papers that have stood the test of time in the field of pediatric radiology, such as the plain radiographic diagnosis of congenital heart disease, acute osteomyelitis, pulmonary sling, and nasopharyngeal lymphoid tissue.

As an attending radiologist Marie soon became one of a group of hospital luminaries, including the legendary pediatrician Waldo Nelson, endocrinologist Angelo DiGeorge, geneticist Hope Punnett, pathologist James Arey, and her colleague in radiology John Kirkpatrick.

Marie and John were exceptional radiologists in an era initially devoid of cross-sectional imaging, and they constantly astounded and delighted clinical colleagues with their diagnoses made from plain radiographs. She continued to embrace new technology as it evolved, and she introduced ultrasonography, nuclear medicine, computed tomography and later magnetic resonance imaging to the hospital.

Marie was a fierce advocate for both her patients and colleagues. She was respected for being forthright and of the 
highest moral integrity. She never hesitated to refuse requests for unnecessary radiologic studies, emphasizing the need in such circumstances for more comprehensive clinical examinations.

She was active on numerous hospital committees in addition to regional and national radiology societies. She served on the board of directors of the Philadelphia Roentgen Ray Society, Pennsylvania Radiologic Society and John Caffey Society of Pediatric Radiology. She served as president of the Society for Pediatric Radiology from 1976 to 1977, holding the distinction of being the first woman president.

During her career she was inducted into the Alpha Omega Alpha Honor Medical Society and was an honorary member of Sociedad Peruana de Radiología, honorary corresponding member of the Australasian Society for Pediatric Imaging, and corresponding member of the Sociedade Brasileira de Pediatria.

She was visiting professor at numerous national hospitals, and despite her great aversion to flying she enjoyed serving as a visiting professor in Sydney, Australia, in 1982.
She served as director of Radiology at St. Christopher's until her retirement in 1992. After retiring, Marie engrossed herself in numerous pastimes and activities, her favorite being seated at her computer. She continuously kept up with advances in computer technology. Perhaps it is no coincidence that her initials were the same as her favorite brand of computer!

She also enjoyed the challenge of jigsaw and intellectual puzzles, and reading mysteries, with Agatha Christie being her favorite author. According to her nephew Jim Dooney, she was "a mean trombone player."

Marie was extremely devoted to her siblings and their families and took an active interest in furthering their education. She also displayed a keen interest in the lives of her radiology associates and their families, always eager to hear of their progress.

Dr. Marie Capitanio was a unique individual who will be forever remembered by her family, friends and radiology colleagues, both regionally and nationally.

Pediatric radiology has lost another giant. 